\title{
Stunting and overweight among children in Northeast Brazil: prevalence, trends (1992-2005-2015) and associated risk factors from repeated cross-sectional surveys
}

Haroldo da Silva Ferreira ${ }^{1 *}$ (D), Gabriela Tenório Albuquerque ${ }^{2}$ (D) Tamara Rodrigues dos $\operatorname{Santos}^{3}$ (D), Rosália de Lima Barbosa ${ }^{3}$ (D) Andressa Lima Cavalcante ${ }^{2}$ (D) Luísa Elvira Cavazzani Duarte ${ }^{2}$ [D and Monica Lopes de Assunção ${ }^{1}$ (D)

\begin{abstract}
Background: A study involving children from Alagoas (Northeast Brazil) revealed that, as a consequence of a drastic reduction in the prevalence of stunting between 1992 to 2005, (22.5 to 11.4\%) combined with an increase in overweight prevalence (6.7 to 9.3\%), the prevalence of these two conditions in 2005 was very close. If these trends were maintained, it is very likely that, at this time, the childhood overweight prevalence has already exceeded that of the stunting. However, no study is available to confirm this hypothesis. The identification of these changes is relevant to the planning and evaluation of public policies. This study aimed to investigate the prevalence, time trends and associated factors with stunting and overweight in children from Alagoas.

Methods: Independent cross-sectional household surveys were conducted in 1992 ( $n=1231), 2005(n=1381)$ and $2015(n=988)$. Data were collected from probabilistic samples of children aged 0-60 months. Stunting was defined by stature-for-age $<-2 \mathrm{sd}$ and overweight by weight-for-stature $>2 \mathrm{sd}$.
\end{abstract}

Results: Between 1992, 2005 and 2015, the stunting prevalence was 22.6, 11.2 and 3.2\% (reduction of 85.8\%), while the overweight prevalence was $6.9,7.5$ and $14.9 \%$ (increase of $115.9 \%$ ), respectively. After multivariate analysis, the following positive associations with stunting were observed in 1992: age group $>24$ months ( $28.3 \%$ vs $14.5 \%$ ), mother with $\geq 2$ children ( $28.8 \%$ vs $12.8 \%$ ), low birth weight ( $28.3 \%$ vs $15.7 \%$ ) and mother with low schooling (29.3\% vs $7.2 \%)$. In 2015 there was a higher prevalence of stunting in males (4.2\% vs 2.2\%), in children < 24 months (4.6\% vs 2.2\%), with low birth weight ( $8.6 \%$ vs 3.0\%) and in those who had mothers with low schooling (7.0\% vs $2.6 \%$ ). Regarding overweight, in 1992 there was higher prevalence for male (9.1\% vs 4.7\%) and in children whose mothers had $\leq 2$ children (8.9\% vs 5.8\%), while in 2015 only birth weight > 4 kg was associated to overweight (27.3\% vs 14.2\%).

\footnotetext{
* Correspondence: haroldo.ufal@gmail.com

${ }^{1}$ Faculty of Nutrition, Federal University of Alagoas, Campus A.C. Simões, BR 104 Norte - Km 96.7 - Tabuleiro do Martins, CEP, Maceió, AL 57072-970, Brazil Full list of author information is available at the end of the article
}

(c) The Author(s). 2020 Open Access This article is licensed under a Creative Commons Attribution 4.0 International License, which permits use, sharing, adaptation, distribution and reproduction in any medium or format, as long as you give appropriate credit to the original author(s) and the source, provide a link to the Creative Commons licence, and indicate if changes were made. The images or other third party material in this article are included in the article's Creative Commons licence, unless indicated otherwise in a credit line to the material. If material is not included in the article's Creative Commons licence and your intended use is not permitted by statutory regulation or exceeds the permitted use, you will need to obtain permission directly from the copyright holder. To view a copy of this licence, visit http://creativecommons.org/licenses/by/4.0/. The Creative Commons Public Domain Dedication waiver (http://creativecommons.org/publicdomain/zero/1.0/) applies to the data made available in this article, unless otherwise stated in a credit line to the data. 
(Continued from previous page)

Conclusions: During the analyzed period, there was a significant decrease in stunting prevalence. At the same time, a substantial increase was observed in the overweight prevalence. Currently, stunting is a problem of low magnitude, while overweight has become a worrying public health problem.

Keywords: Child nutrition disorders, Protein-energy malnutrition, Obesity, Nutrition surveys, Preschool child

\section{Background}

Nutritional transition is a process that has happened all over the world [1]. While this process is not complete, problems caused by the double burden of malnutrition (DBM) prevails in the population. DBM is the coexistence of nutritional deficiencies (micronutrient deficiencies, underweight, and childhood stunting and wasting) and overweight/obesity affecting countries, households, and individuals [2]. Both overweight/obesity and nutritional deficiencies in general are risk factors for adverse health consequences throughout the life-course [3].

Findings of a study involving about 130 million children, adolescents, and adults from 200 countries worldwide demonstrated that, from 1975 to 2016, the protein-calorie malnutrition prevalence in children under 5 years old has been systematically decreasing. On the other hand, the rising trends in children's obesity have plateaued in many high-income countries, although at high levels, but continues to grow at an accelerated rate in other regions of the world. These differences are associated with the level of the nations' economic development. Thus, in the poorest regions of the world there may be a double burden of nutritional problems [4].

Although at the individual level, stunting is not a synonym of malnutrition, in a population (epidemiological) approach, this condition is considered the most prevalent form of child malnutrition [5, 6]. In a publication by the WHO, it is reported that, in 2016, there were $22.9 \%$ or 154.8 million children under 5 years with stunting in the world [7].

Stunting is defined as impaired growth and development that children experience due to the combined effects of poor nutrition, repeated infection, and inadequate psychosocial stimulation [8]. According to the World Health Organization (WHO), factors that go beyond hunger and food availability are involved in the etiology of stunting. Child stunting is a process that occurs mostly in the first 1000 days after conception, as a result of the interaction between several characteristics, such as socioeconomic status, food intake, infections, maternal health, infectious diseases, micronutrient deficiencies and environmental conditions [7]. In this way, the adequacy of linear growth is a good indicator of children's general health [8] and provides an accurate indicator of inequalities in human development [6]. Since stunting, once established, is difficult to be reversed, and that while a nutritional deficiency can cause stunting, there are many other non-nutritional causes, which reduces the effectiveness of nutritionspecific interventions, it calls for preventive measures articulated in multiple development sectors and requires a trans-disciplinary response $[9,10]$.

Childhood obesity is a public health problem that has shown increasing in prevalence in many countries around the world. This has caused great concern due to the comorbidities associated with excess body weight that occurs already during childhood (type 2 diabetes mellitus, hypertension, nonalcoholic fatty liver disease, obstructive sleep apnea, and dyslipidemia) and, especially, in adulthood, given that the obese child is more likely to become an obese adult. Only a small fraction of obese children have an underlying endocrine or genetic cause for their weight gain. Thus, the main etiology for the accumulation of fat above the level considered healthy (which defines the condition of obesity) is a positive energy balance. This is due to excessive caloric intake and/or a low pattern of physical activity, associated with a metabolic genetic predisposition for the accumulation of body fat $[5,11-13]$.

In Brazil, the Ministry of Health is an institution of the Federal Government that is responsible for elaborate public policies to promote the Brazilian people's health. Thus, adequate estimates of the prevalence of the main problems that affect the population are necessary. In this aspect, there are difficulties due to the unequal pattern of economic development existing among the different states of the federation and the consequent impact on their respective epidemiological profiles [14]. The states located in the south/southeast region have high Human Development Indexes (HDI), while those belonging to the north/northeast region fall within the category of median HDI. For example, the HDI of the state of Santa Catarina is 0.774 , while Alagoas has an HDI of 0.631 (these states are located in southern and in northeastern Brazil, respectively). Considered in the whole, Brazil has HDI of 0.755 (high HDI) [15].

Socioeconomic differentials are strongly reflected in the population's nutritional status. In 1989, when there was the first large national survey involving the nutritional assessment of pre-school children from the different Brazilian states, the prevalence of stunting in Alagoas was more than seven times higher than that observed in the state of Santa Catarina (36.8\% vs $4.9 \%)$ [16]. 
In addition to the lowest HDI and higher prevalence of stunting, Alagoas presents the worst economic and social indicators when compared to the other states of the country, such as higher rate of illiteracy and lower average family income [14]. Despite this, a study published in 2013 revealed that, as a consequence of a drastic reduction in the prevalence of stunting between 1992 to 2005 (from 22.5 to $11.4 \%$ ) combined with a significant increase in overweight prevalence in the same period (from 6.7 to $9.3 \%$ ), the prevalence of these two conditions among preschool children, in 2005, was very close. Maintained these trends, it is very likely that, at this time, the childhood overweight prevalence has already exceeded that of the stunting. However, no study is available to confirm this hypothesis. The identification of these changes in nutritional profiles is extremely relevant for the planning and evaluation of public policies.

The objective of this study was to describe the characteristics (prevalence, temporal trend and associated factors) of stunting and the overweight in children from a state in Northeast Brazil.

\section{Methods}

This is a time-series study, based on three household surveys conducted in 1992, 2005 and 2015. In both, the sampling processes allowed the obtaining of representative samples of children under 5 years old in the state of Alagoas.

\section{Sampling procedure 1992 Survey}

The sample was defined using a procedure consisting of three stages. At each stage were successively and randomly selected the municipalities (20 out of a total of 102), the census tracts (eight per municipality) and households (15 per census tracts). The final sample analyzed consisted of 1228 children. According to Victora et al. [17] with this sample, it would be possible to obtain estimates of the most common health problems, with an acceptable margin of error. A detailed description of the sample design is available in another publication [18].

\section{Survey}

In the sample size calculation, the authors considered the following parameters: prevalence of deficit $(<-2 \mathrm{z}$ scores) of height-for-age of $9.5 \%$, a margin of error of $1.5 \%$, confidence interval of $95 \%$ and an estimated population of 308 , 000 individuals. For this, 1461 children would be needed. To achieve this number, a procedure similar to that used in the 1992 survey was used (selection of 20 among 102 municipalities in Alagoas and 8 census sectors in each selected municipality), except in the 3rd stage, in which instead of eight, nine households were selected per sector. The final sample consisted of 1381 children. More details are available elsewhere [18].

\section{Survey}

The original study aimed to estimate the prevalence and factors associated with food insecurity in families in the state of Alagoas. Socioeconomic, demographic and anthropometric data were investigated for all individuals in a representative sample of 3366 families [14]. Specifically for this study, all children under 5 years old living in the selected households were included, excluding those with anatomical or pathological alterations that could alter the anthropometric evaluation. In the sample calculation (a posteriori) was considered: overweight as a dependent variable, with a prevalence of $9.7 \%$ [19], a universe of 328,000 children, margin of sample error of $2.5 \%$ and 1.5 for correction of the effect of the complex design. For a $95 \% \mathrm{CI}$, with $10 \%$ more to cover possible sample loss, 946 children would be needed. The sample size analyzed was 988 individuals. The StatCalc tool from Epi-info, version 7.2.1.0 (Centers for Disease Control and Prevention - CDC, Washington, USA), available at https:// www.cdc.gov/epiinfo/index.html, was used to perform the calculations.

The sampling process was similar to those carried out in the 1992 and 2005 surveys: 1) drawing of 30 municipalities (out of a total of 102); 2) four census tracts per municipality, guaranteeing the proportion between the urban and rural areas; 3 ) one block in each of the census tracts, and; 4) a household in each block and the 30 consecutive homes to it. Thus, 31 families were visited. The original work was published by Costa et al. [14], in which further details can be found.

\section{Data collection}

In all the three surveys, the data were obtained by adequately trained and supervised interviewers. All procedures and instruments were tested in a pilot study. Information was obtained in the respective households through interviews applied to mothers or guardians of the children. On that same occasion, anthropometric measurements were also obtained. Although the equipment used in each of the three surveys was not exactly the same, they were systematically calibrated and tested against a standard measure, so that this aspect certainly did not interfere with the reliability of the results.

\section{Dependent variables}

The dependent variables were stunting, defined by stature-for-age $<-2$ standard deviations (sd), and overweight, identified by weight-for-stature $>2 \mathrm{sd}$. The classification of the children's nutritional status was performed after processing of the variables weight, age, sex and stature in the Anthro v3.2.2 software (World Health Organization - WHO, Geneva, Switzerland) to obtain the $\mathrm{z}$ scores of the indices stature-for-age and weight- 
for-stature according to the WHO anthropometric standard [20].

In 1992, body weight was measured with a Salter type portable scale (CMS PBW-235; CMS Weighing Equipment, London, England), accurate to $100 \mathrm{~g}$; in 2005 a portable electronic scale was used, with a capacity of $180 \mathrm{~kg}$ and subdivisions of $100 \mathrm{~g}$ (Marte PP180 Balanças Ltda., São Paulo, Brazil); in 2015 a digital scale (Charder MS6121R, Taichung City, Taiwan) was used, with a capacity of $250 \mathrm{~kg}$ and a precision of $100 \mathrm{~g}$. In the three surveys, the scales were calibrated weekly against standard weight.

Children older than 24 months had their stature measured in the standing position with a vertical stadiometer, while in children aged 24 months or less the length was measured with the child in the supine position, using a horizontal anthropometric ruler. The equipment in all the surveys included a non-flexible measuring tape, accurate to $0.1 \mathrm{~cm}$.

\section{Independent variables}

Through interview following questions contained in a structured form, demographic and socioeconomic variables were investigated: sex, age range ( $\leq 24$ months; $>24$ months), birth weight (obtained through the "Child's Health Card" as a continuous variable but analyzed as a categorical variable: normal: 2500 to $3999 \mathrm{~g}$; low: $<2500 \mathrm{~g}$ and; high: $\geq 4000 \mathrm{~g}$ ), number of people living in the household $(\leq 4 ;>4)$, area of residence (urban; rural), and, about mother, number of children $(\leq 2 ;>2)$, schooling ( $\leq 4$ years; $>4$ years) and age range ( $\leq 20 ; 20.1$ to 39.9 and $\geq 40$ years).

About the area of residence, the Brazilian Institute of Geography and Statistics (IBGE) defines an urban area as that corresponding to towns (municipal headquarters), villages (county headquarters) or isolated urban areas. All territory out of the limits of an urban area is considered as a rural area. Legally, these territorial limits are established by municipal law. In general, an urban area is characterized by higher population density, greater infrastructure of public services and an economy based on industry and commerce. In rural areas, there is lower demographic density, greater distance between households, poor infrastructure of public services and agriculture and livestock is the main economic activity [21]. As already mentioned, in the sample composition of the three surveys analyzed in the present study followed the definition used by IBGE when the establishment of census sectors in the municipalities. This definition was constant throughout the analyzed period.

\section{Statistical analysis}

The data were typed in an independent double entry in a form generated in Epi-info, version 3.5.4. After the typing errors corrections and outliers exclusion, the data were submitted to statistical analysis with the help of Stata 12.0 software (Stata Corp., College Station, USA).

Since the variables showed adherence to the normal distribution, according to the Levene and KolmogorovSmirnov tests, the one-way ANOVA with Bonferroni post-hoc test was used to compare means of $\mathrm{z}$ scores.

The observed increases (or decreases) in the prevalence at the third survey concerning the first, were described as percentages, using the following equation: [(prevalence in 2015 - prevalence in 1992)/prevalence in 1992] $\times 100$.

Trends analysis in the dependent variables used Poisson regression to estimate prevalence ratios (PR). Increases and decreases were defined as $\mathrm{PR}>1$ or $\mathrm{PR}<1$, respectively, and the values obtained in 1992 were used as the reference.

To identify the factors associated with stunting or with overweight in the 1992 and 2015 surveys, respectively, multivariate Poisson regression was used. The independent variables that exhibited less significance (higher $p$ value) were gradually excluded from the model (backward elimination). In the final model, only those with $p<0.05$ remained, a condition that was assumed in all the situations of the statistical analysis to designate statistical significance. However, to avoid not neglecting the possible effect of variables that approached the statistical significance, it was designated as of marginal significance those variables that were between $p>0.05$ and $p \leq 0.1$.

To identify possible problems caused by multicollinearity, we examined the correlation matrix. We found that there were no predictors that showed a high correlation with any of the other predictors (multicollinearity arises when at least two highly correlated predictors are assessed simultaneously in a regression model). Additionally, the variance inflation factor (vif) test was applied, with no evidence of multicollinearity in the final models obtained.

Data analysis was performed using the svy command in Stata, since the data were from complex sampling design.

\section{Ethical aspects}

The Research Ethics Committee of the Federal University of Alagoas approved the projects for the 2005 surveys (process \# 010102 / 2003-35) and 2015 (process \# 010102/ 0355). All the participants in the study were informed about the study objectives, its risks and benefits, and the children's mothers or guardians signed the Free and Informed Consent Form. The use of the database of the 1992 survey was carried out with the consent of the holder of the rights of this material (Prof. Dr. Cesar Gomes Victora, from the Federal University of Pelotas, RS, Brazil).

\section{Results}

A total of 1231 children were investigated in 1992, 1381 in 2005 and 988 in 2015. The prevalence of underweight 
(5.9, 3.2 and $2.2 \%)$ and wasting (1.4, 0.9 and $2.1 \%)$ at the time of these surveys were, respectively, of low magnitude. For this reason, these conditions will not be explored in the present study.

In 1992 the prevalence of stunting was $22.6 \%$, decreasing to $11.2 \%$ in 2005 and to $3.2 \%$ in 2015 (Table 1). Considering the whole period, there was a decrease in the order of $85.8 \%$ ( $P R=0.14,95 \%$ CI: $0.10-0.20$ ). The same trend was observed with age groups, however in different magnitudes: In 1992, the prevalence among older children was almost twice that of younger children $(28.3 \%$ vs $14.6 \%$ ), while in 2015 there was a reversal of this profile (2.2\% vs $4.6 \%)$, but at a drastically lower level.

The mean $z$-score of the height-for-age index increased from $-0.94 \pm 1.61$ in 1992 to $-0.46 \pm 1.35$ in 2005 and to $0.02 \pm 1.28$ in 2015 . The difference was statistically significant in all the comparisons.

Regarding overweight (Table 1), the prevalence in 1992 was $6.9 \%$, increasing to $7.5 \%$ in 2005 and to $14.9 \%$ in 2015 , representing a total increase of $115.9 \%$ ( $P R=$ 2.15, 95\% CI: 1.67-2.78). Unlike the increase observed in 2015 compared to 1992, the increase observed in 2005 did not reach statistical significance. Similar results were observed comparing children younger than 24 months with those with higher ages. Considering each of the three surveys, there was no significant difference in the overweight prevalence among the children according to these age groups $(p>0.05)$. Considering the total number of children, a significant increase in the $\mathrm{z}$ scores of the weight-for-height index was observed only in 1992 vs 2015 comparison, which increased from $0.45 \pm 1.07$ to $0.64 \pm 1.36$.

Comprehensively, there was an important reversal in the prevalence magnitude of the nutritional disorders analyzed, as evidenced in Fig. 1. Stunting, which was a severe public health problem in 1992, lost its epidemiological relevance for overweight in 2015, and the crossing of the trend curves that characterized this change occurred in mid-2005.

Table 2 shows the distribution of the sample socioeconomic and demographic characteristics according to the three surveys and the respective prevalence of stunting and overweight. In the period within 1992, 2005 and 2015 there was a significant reduction $(p \leq 0.05)$ in the proportion of rural residents, mothers with more than two children, children with low birth weight, children with high birth weight, mothers with lower schooling, mothers under the age of 20 and households with more than four residents.

In this unadjusted analysis, stunting was associated (higher prevalence) with the following conditions: Male sex (only in 2005), age group > 24 months (in 1992) and $\leq 24$ months (in 2015), low birth weight (1992, 2005 and 2005), living in a domicile with more than four residents (in 1992), living in rural areas (1992 and 2005), being a son of a mother with more than two children (in 1992 and 2005) and with low schooling (in the three surveys) and age $\geq 40$ years (in 1992). On the other hand, the following conditions were associated with a higher prevalence of overweight in 2015: Female sex (only in 1992), being a son of mothers with $\leq 2$ children (only in 1992), and high birth weight (2005 and 2015).

The adjusted analysis was performed to verify which factors were independently associated with stunting and overweight in 1992 (Table 3) and 2015 (Table 4).

The following conditions were associated with stunting in 1992 (Table 3): age group with more than 24 months (28.3\% vs. $14.5 \%, P R=1.85,95 \%$ CI: $1.31-2.63)$, low birth weight $(28.3 \%$ vs. $15.7 \%, \mathrm{PR}=1.72$, 95\% CI: 1.19 $2.49)$, mother with three or more children $(28.8 \%$ vs. $12.8 \%, \mathrm{PR}=1.64,95 \% \mathrm{CI}: 1.15-2.35)$, and mother with low schooling $(29.3 \%$ vs. $7.2 \%, \mathrm{RP}=3.23,95 \%$ CI $2.01-$ 5.22). In 2015 (Table 4), the stunting prevalence was lower in females $(2.2 \%$ vs. $4.2 \%, \mathrm{PR}=0.38,95 \%$ CI: $0.17-$ $0.83)$ and in children older than 24 months $(2.2 \%$ vs. $4.6 \%, \mathrm{PR}=0.43,95 \%$ CI: $0.20-0.91$ ). Higher prevalence was observed among children with low birth weight ( $8.6 \%$ vs. $3.0 \%, \mathrm{PR}=2.99,95 \%$ CI: $1.33-6.70)$ and in the mothers' sons with low schooling $(7.0 \%$ vs. $2.6 \%, \mathrm{PR}=$ 3.10; 95\% CI: 1.52-6.33).

Concerning overweight, in 1992 lower prevalence (Table 3) were found for female children $(4.7 \%$ vs. $9.1 \%$, $\mathrm{PR}=0.50,95 \% \mathrm{CI}: 0.32-0.78)$ and those who had mothers with three or more children $(5.8 \%$ vs. $8.9 \%$; $\mathrm{RP}=0.66 ; 95 \% \mathrm{CI}: 0.44-1.0$ ). In 2015 (Table 4), only born with more than $4 \mathrm{~kg}$ was associated with a higher prevalence of overweight ( $27.3 \%$ vs. $14.2 \%, \mathrm{PR}=1.91$ and 95\% CI: $1.24-2.95)$.

\section{Discussion}

The stunting prevalence in children under five has declined substantially in the last three decades worldwide. Concomitantly, there was an increase in overweight prevalence. This transition in the child's nutrition profile occurred in different proportions in both developed and developing countries [22].

The results of the present study demonstrate that this process has also been occurring in Alagoas, so that during the period investigated (1992-2015), there was an $85.8 \%$ decrease in the stunting prevalence and a $115.9 \%$ increase in the overweight prevalence.

Alongside these observations, during this period, the child mortality rate in Alagoas fell from 88.7 per 1000 live births to 14.6 per 1000 live births [23]. It is very likely that the factors associated with the reduction in the number of stunted children also contributed to the decrease in the observed mortality rate, since stunting and child mortality are correlated variables [5] and both 


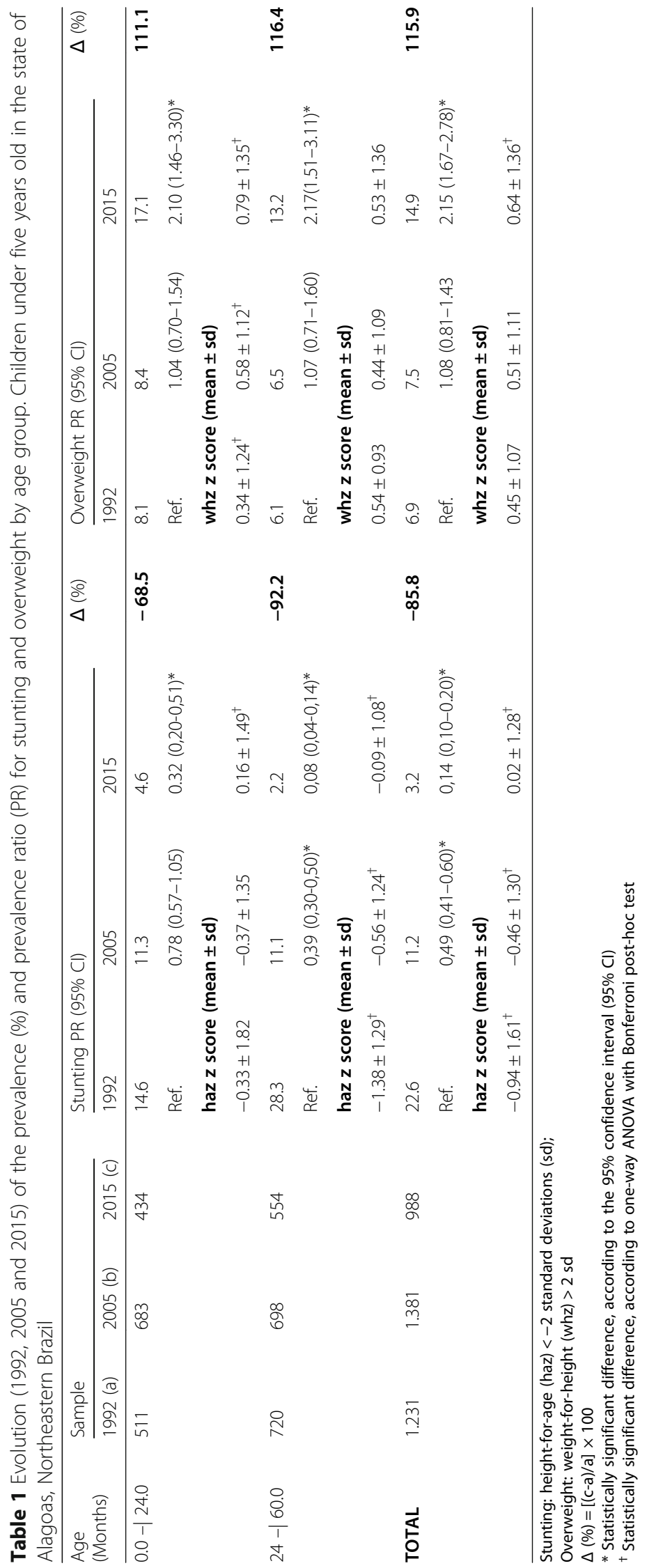




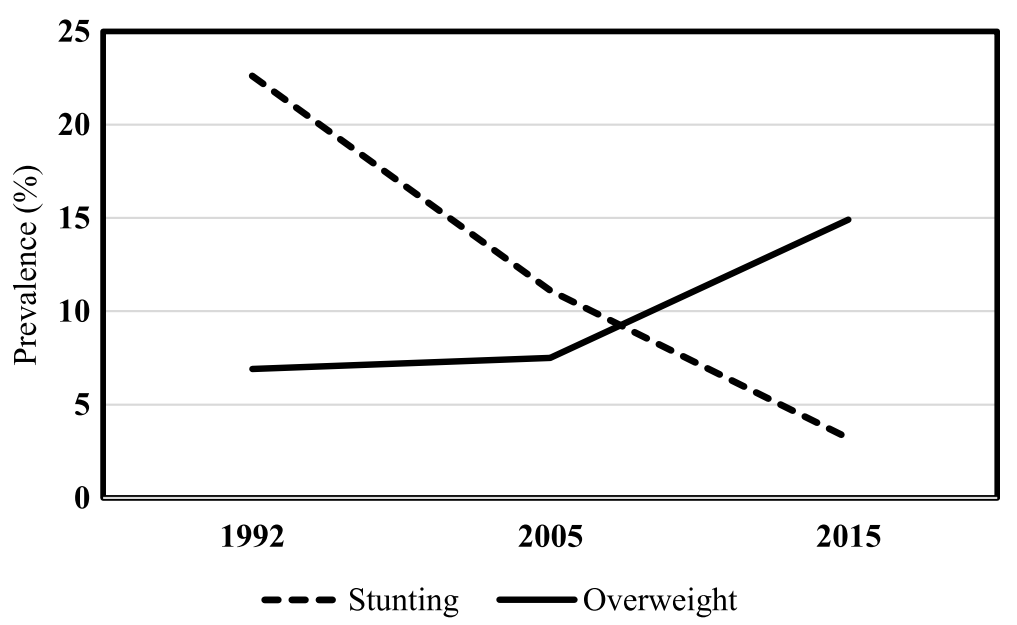

Fig. 1 - Time trends (1992, 2005 and 2015) of the stunting and overweight prevalence. Children under five years old in the state of Alagoas, Northeastern Brazil Stunting: height-for-age $<-2$ sd; Overweight: weight-for-height $>2$ sd.

regulated, perhaps, by factors such as the socialeconomic-political-emotional environment.

Considering the national context, these findings occurred in parallel with the improvement of both economic and health indicators. Gross Domestic Product (GDP) per capita, which in 1996 was R\$ 5219.36, increased to $\mathrm{R} \$ 29,466.85$ reais in 2015 (About 1104.90 and 6237.92 US dollars, respectively, on March 10, 2020) [24]. Neonatal mortality dropped from $23.6 \%$ live births in 1992 to $9.4 \%$ live births in 2015. Similarly, the mortality of children under 5 years was reduced from $57.2 \%$ to $15.7 \%$ in the same period) [25].

This considerable decline placed the prevalence of stunting in Alagoas (3.2\%) at a level lower than the world estimate (22.2\%) for children of the same age, as estimated by international institutions. This discrepancy can be explained by the high prevalence found in Asia and Africa, considerably raising the global average. Analyzing the data stratified by continent, it is observed that the prevalence seen in 2015 in Alagoas is still below the average in South America (7.5\%), getting close to the average attributed to the United States region (2.3\%) [26].

The data presented herein are consistent with the results of a recent study that compared the health indicators measured in 1990 with those measured in 2015 in Brazil and its states [27], highlighting the expressive reduction in the prevalence of child's stunting in the period. Between 1990 and 2015, stunting prevalence dropped from 19th to 30th place in the ranking of causes of infant mortality. The study showed that inadequate feeding was the main contributor to the overall burden of disease in the country, particularly for noncommunicable diseases and, because of the worrying rise in the overweight prevalence, the authors claim that it is fundamental to invest in measures to deter this increase, such as regulatory rules to tax unhealthy foods like softdrinks and ultra-processed foods.

The last survey that evaluated children's health in Brazil was the National Survey of Demography and Health of Children and Women, conducted in 2006 (PNDS-2006), which found that the stunting and overweight prevalence was 7.0 and $7.3 \%$, respectively [28]. These data corroborate with our results that indicated that from 2005 onwards, there was the intersection of the trend curves of the analyzed nutritional disorders. However, although the overweight prevalence has been similar ( $7.3 \%$ vs $7.5 \%$ ), stunting was 4.2 percentage points higher in Alagoas (7.0\% vs 11.2\%).

Anthropometric surveys performed on probabilistic samples of the Brazilian population of children under five in the 1970s, 1980s and 1990s indicated a systematic concentration of stunting in the Northeast region. In 1989, the National Survey on Health and Nutrition, although indicating reduction of stunting in all the Brazilian regions, showed that the decline was relatively less pronounced in this region, which had a prevalence of height-for-age deficits three times as high as that found in the Country's Center-South regions, a fact attributed to differentials in socio-economic development and access to the public services infrastructure [29].

Even under these circumstances, the stunting prevalence in Alagoas in 2005 (11.3\%) was almost twice that of the Northeast in 2006 (5.9\%) [29]. However, the rapid decline in the stunting prevalence in Alagoas in the 1992-2015 period (22.6 to 3.2\%) took this nutritional disorder from the level of a medium public health problem to a problem of low magnitude [30].

These changes were consistent with modifications in families' socioeconomic conditions, such as an increase in maternal education and a decrease in the percentage of households with mothers with three or more children. 


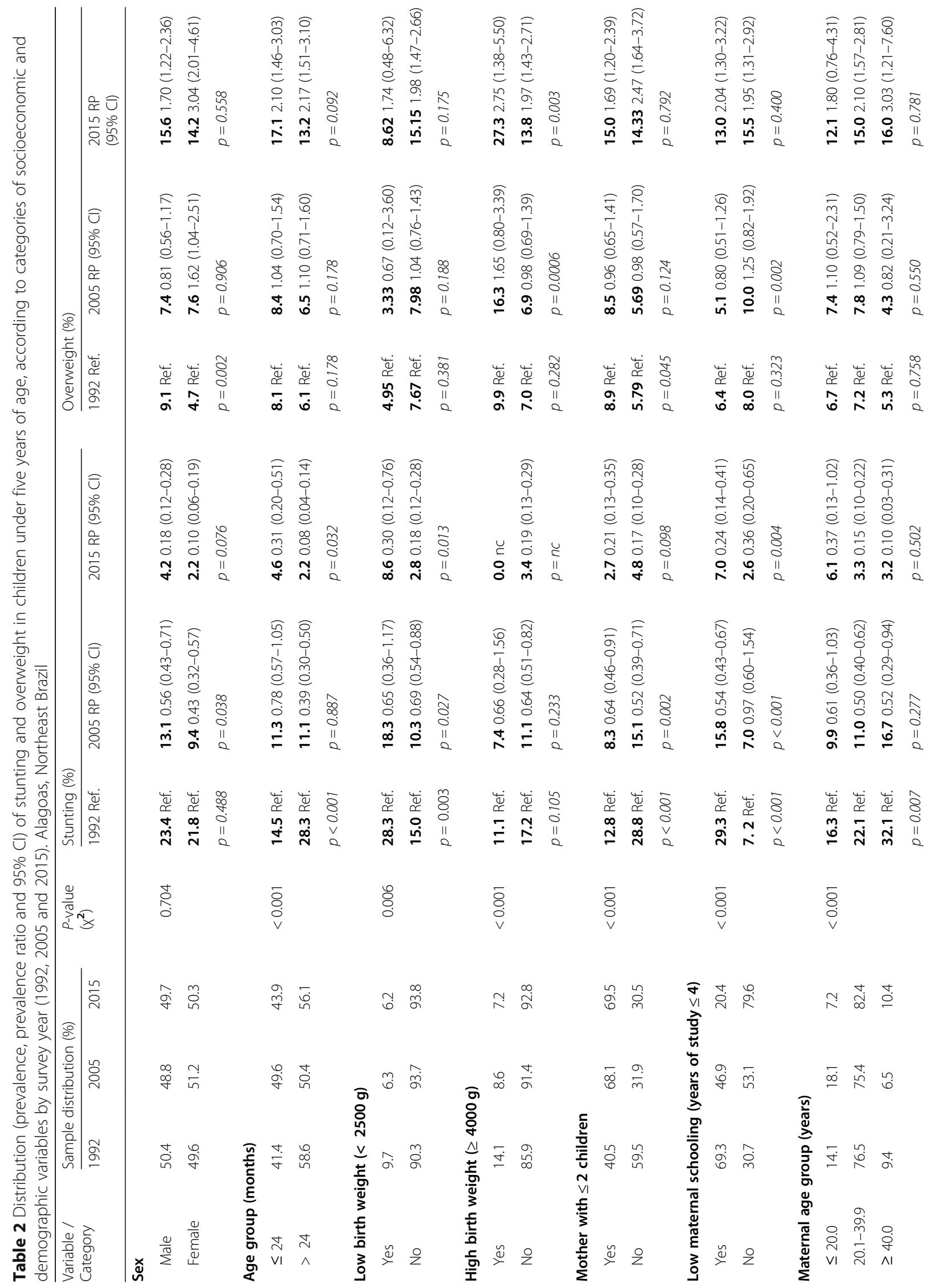




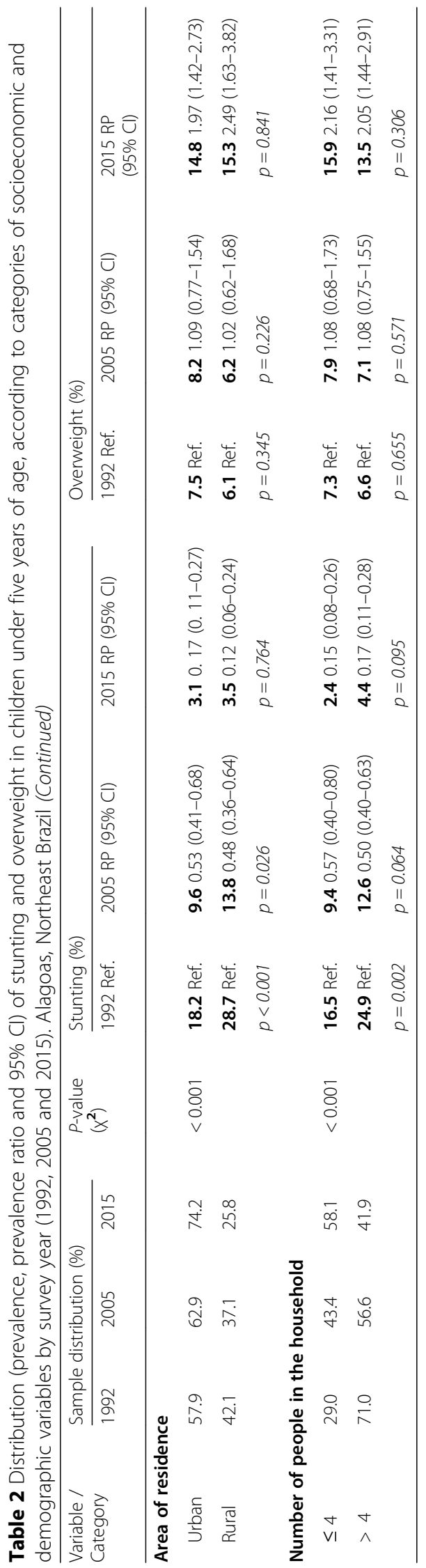


Ferreira et al. BMC Public Health

(2020) 20:736

Page 10 of 15

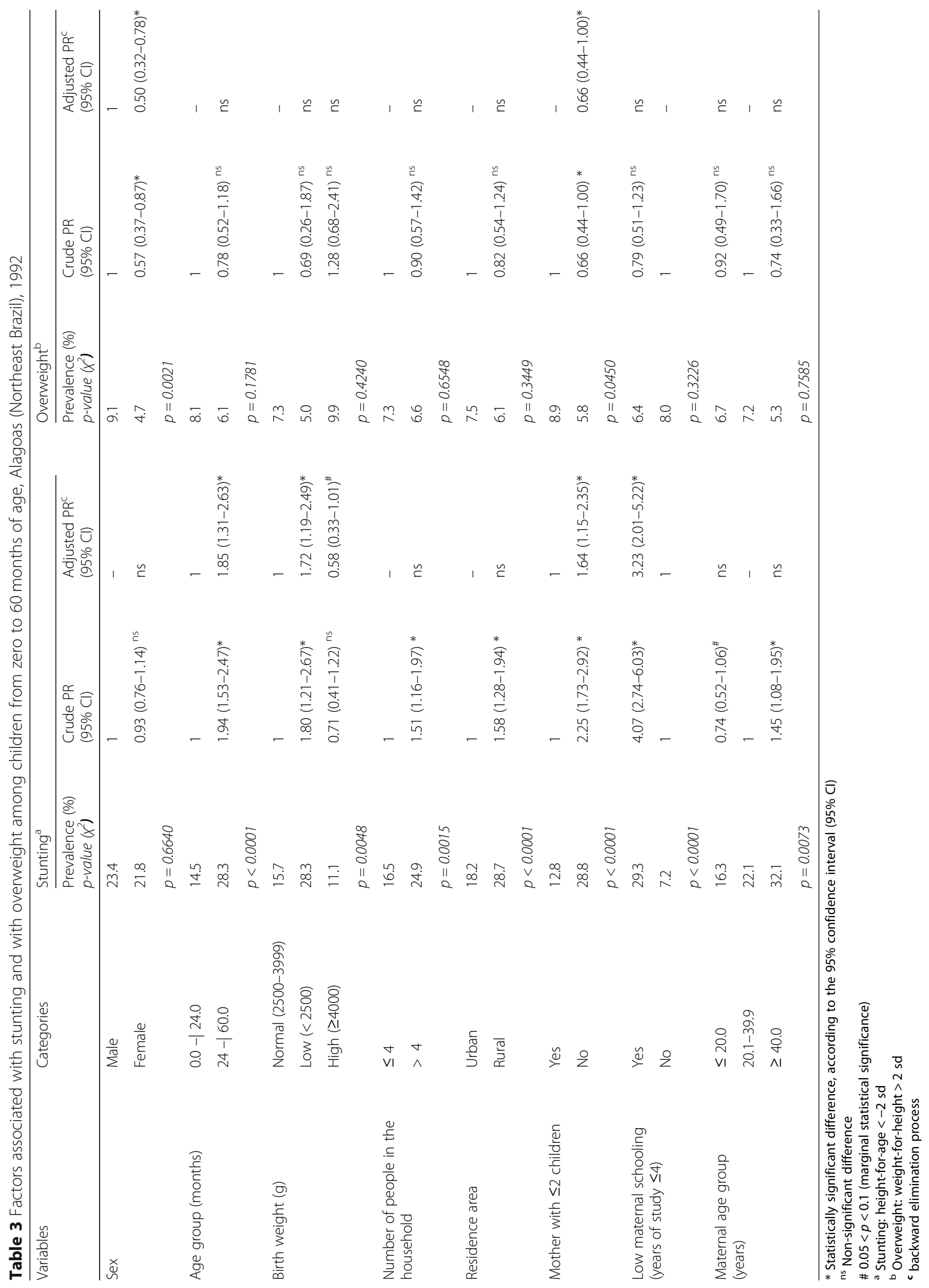


Ferreira et al. BMC Public Health $\quad$ (2020) 20:736

Page 11 of 15

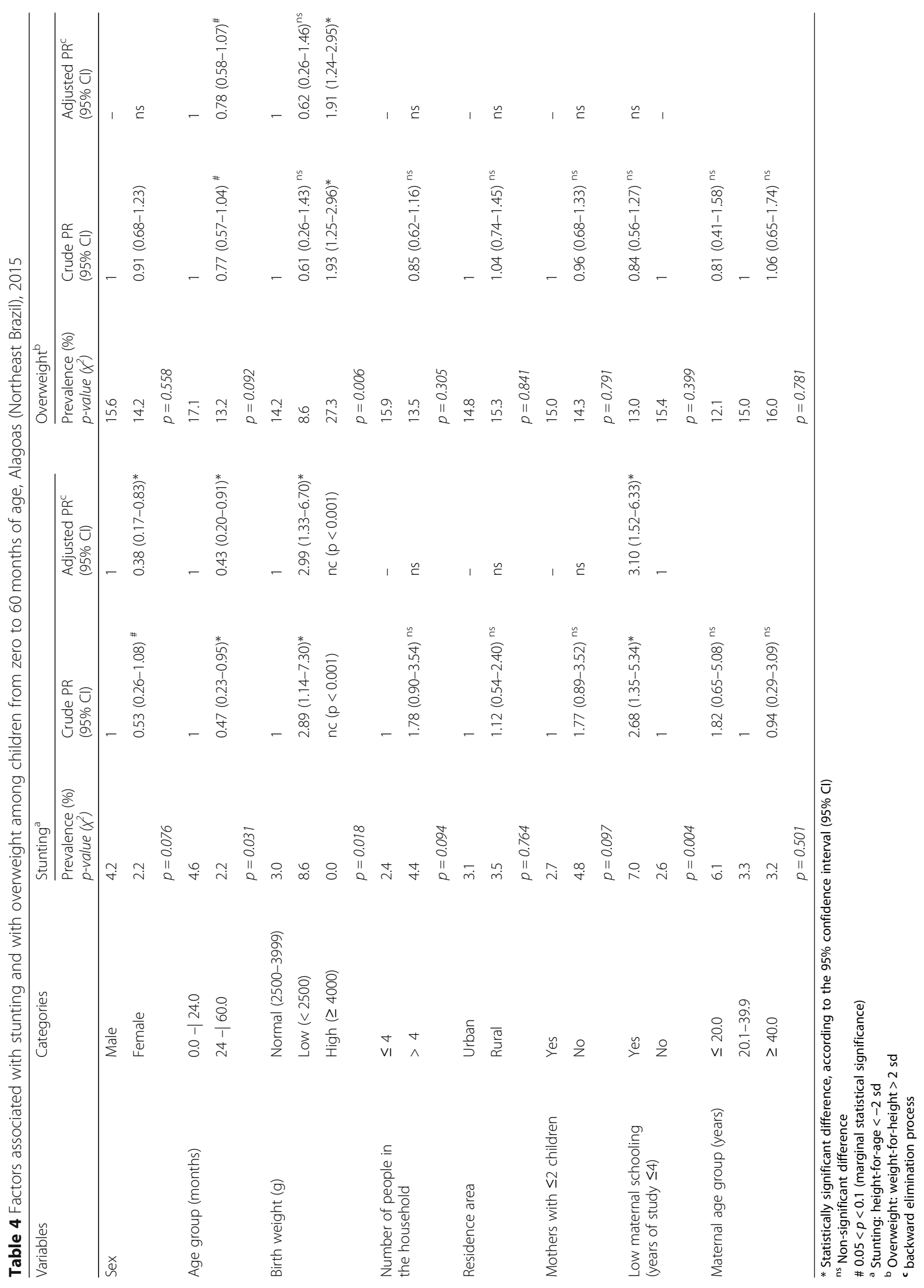


A study conducted by Lima et al. [29] corroborates the findings of the present research by indicating that the decline in stunting in northeastern Brazil was associated with changes in socioeconomic conditions of more impoverished families, which showed improvements in purchasing power, maternal education, basic sanitation and access to health care.

The period analyzed herein, in which there was a significant change in the children's nutritional status, encompassed the governments that promoted the country's re-democratization, implementing a series of public policies that undoubtedly contributed to the improvement of the population's health level. During this period, several social protection programs were performed, and "Sistema Único de Saúde" (Unified Health System) was consolidated, guaranteeing free and universal access to all citizens in their demands for health care [27]. In 2002, during the United Nations General Assembly on children, Brazil committed to reducing by at least a third of stunting prevalence in children [31, 32]. The anticipated achievement of this goal was published in 2010 by the Ministry of Health, attributing it to improved household socioeconomic conditions and access to essential public services, despite regional inequalities [33]. In this aspect, Souza et al. [34] report that:

\section{Regarding successful food security policies, Brazil has been known worldwide for reducing food insecurity by improving food access, income generation, supporting the food production by small farmers, and enhancing food security governance including civil society organizations. Most importantly, alongside these developments, Brazil built a robust legal and institutional framework for food security, transforming the fight against hunger into a state obligation. These political and social commitments were established in a period marked by strong economic growth and reduction of unemployment. As a result, poverty and severe food insecurity were drastically reduced from 2004 to 2014 in Brazil.}

Therefore, ensuring better socioeconomic conditions for the population, along with actions that promote universal access to education and health care is a fundamental strategy in the fight against hunger and child's stunting.

As already mentioned, the prevalence of overweight evolved in the opposite way to that of stunting, showing an upward trend during the analyzed period, going from an irrelevant situation to a worrying public health problem [30] in this population.

The rise in the childhood overweight prevalence in Alagoas in recent decades has been higher than that observed worldwide. Reports of UNICEF/WHO/World Bank demonstrated that in 27 years (1990-2017) the worldwide overweight prevalence in children under 5 years increased from 4.8 to $5.6 \%$, that is, the overweight prevalence in Alagoas in 1992 (6.9\%) exceeded that identified in 2017 globally. The prevalence found in 2015 (14.9\%) in the state was similar to that found in South Africa (13.7\%) in the last global report (2017). When specifically assessing South America, the prevalence in Alagoas in 2005 was similar to the current prevalence in the continent $(7.7 \%)[22,26]$.

The increase in the childhood overweight prevalence in Brazil occurred mainly in lower economic development regions (North and Northeast), especially in the states of Alagoas, Ceará, Amazonas and Amapá [35]. Also, the rate of increase in the overweight in the country was faster in the child's population than among adults [36].

A study that analyzed the temporal trend (1989, 1996 and 2006) of overweight in Brazilian preschoolers (24 to 59 months) identified an increase of $160 \%$ in the period, with a prevalence that increased from 3\% in 1989 to $7.8 \%$ in 2006 [37]. This last value was slightly higher than that found in 2005 (6.5\%) in children from Alagoas of the same age group. However, the absence of more recent national surveys and involving the same age range of the present study ( 0 to 59 months) makes it impossible to compare the trend observed since 2005 in Alagoas with the national trend.

Among the associated factors, low birth weight was one that exhibited the most consistent results, since it was a risk factor for stunting in both 1992 and 2015 surveys. Consistent with this fact, our investigations also revealed a drop in the low birth weight prevalence during this same period, going from 9.7 to $6.2 \%$, respectively. On the other hand, high birth weight was independently associated with overweight prevalence in 2015. This relationship was not verified in 1992, possibly due to the very low prevalence of this nutritional condition on this date. Birth weight is a variable that expresses the nutritional status and intrauterine fetal development, possibly reflecting the influence of the mother's eating habits during pregnancy $[38,39]$.

As low birth weight, low maternal education was also an independent risk factor for stunting in the 1992 and 2015 surveys. In general, greater education access contributes to nutritional deficits reduction. Although in this study there was no significant association between higher education and overweight, the overweight prevalence in children observed in recent decades had a direct relationship with the level of maternal schooling [28] and therefore with better socioeconomic conditions, which is in line with the expectations for developing countries. In Brazil and other emerging countries, 
studies have shown a positive association between overweight prevalence in children and family socioeconomic conditions [40-43]. According to Gupta et al. [43], this association would be due to the highest foods purchasing power, with greater access to fast-foods and ultraprocessed foods (high-calorie density), combined with a more sedentary lifestyle.

The number of children was also consistent as an associated factor because "mother with three or more children" was a risk factor for malnutrition in both 1992 and 2015 survey, showing that more considerable investments in education are needed to improve the population's health standard. In contrast, mothers with up to two children was a risk factor for overweight (only in the 1992 survey). Regarding the higher stunting prevalence among children whose mothers had three or more children, it can be speculated that, under this condition, the mother would have less time to take care of her children and, additionally, there would be less per capita availability of food at home. A Chinese study revealed that being a singlechild is about four times more likely to be overweight than those having siblings, leading the authors to conclude that China's one-child policy might have contributed to its rising childhood obesity rates [44].

Being male was a risk factor for stunting in 2015 and for overweight in 1992, which is a difficult situation to explain, except for the possible relationship with the prevalence magnitude. Difference was only observed when there was a low prevalence, such as stunting in 2015 (3.2\%) and overweight in 1992 (6.9\%), when boys were more affected. Given this, there is a possibility that due to the small number of individuals in the affected categories, there has been a reduction in consistency in terms of statistical power. That is, if there is a differential in terms of greater susceptibility to stunting or overweight due to sex, it was not possible to demonstrate safety in this work.

For the age group, there was association only with stunting, however oppositely: in 1992 height deficit affected children older than 24 months, while in 2015 this situation was reversed, in a way that younger children were more affected. Some authors have attributed the decline in the stunting prevalence to improvements in socioeconomic conditions and greater access to essential public services such as education, health, and sanitation among the Brazilian population. Thus, it can be assumed that children older than 24 months were more exposed and dependent on environmental conditions and therefore were more affected by stunting in 1992 . With the improvements established in 2015, external factors began to interfere less, so that biological factors would better explain the higher prevalence observed among younger children.

Considering the influence of social, economic and political determinants on the children's nutritional status
[45], it is evident the importance of the results published herein to establish a baseline to be used as a parameter in future evaluations, especially because of the current scenario of political transition experienced in Brazil $[34,46]$.

The stunting at a global level, after years of decline, increased from 2015 to 2016 due to the economic and political crises that have been occurring in many developing countries. The economic downturns impact on food security suggests a threat to food security in Brazil, as, since 2014, the country has faced a significant economic crisis along with high political instability. As demonstrated by Costa et al. [14] in a representative probabilistic sample of families from the state of Alagoas, there was a marked increase in the food insecurity prevalence during the current Brazilian crisis. In the context of this crisis, in 2016, there was a presidential impeachment, aggravating the country's political instability. At the same time, there was a deterioration in many social indicators, such as income and unemployment. Due to inflation, there was an increase in food prices. "As a result, the Brazilian government responded with austerity measures, which led to reduced funding for many social and food security policies" [34].

Completing this scenario, the inaugural speech of the current President of the Republic of Brazil, which took place on the first day of 2019, was the first since the end of the military dictatorship in 1985 not to mention the need to address poverty and inequality [47]. Still in the first day of government, extinguished the National Food and Nutrition Security Council (Conselho Nacional de Segurança Alimentar e Nutricional), a channel linked to the Presidency of the Republic to dialogue with civil society and to formulate public policies to promote food security in the country. All this has caused concern to many public health professionals in Brazil, because of the real possibility that the country reappears on the UN hunger map, from which was removed in 2014.

Therefore, the current scenario in Brazil is characterized by the weakening of government policies to reduce inequality and poverty, implemented especially from the 2000 s, a fact that has been causing increase in inequalities of a social, political, economic and educational nature, conditions strongly associated with food insecurity, malnutrition and deterioration of the population's health and quality of life [48, 49], mainly of the children.

Contrary to the important advances presented by Brazil in the fight against hunger and nutritional deficiencies, the rise in the overweight prevalence was identified. This current epidemiological scenario is worrisome due to the harmful health consequences triggered by obesity. Excessive body fat in early life increases the risk of these children to become obese adults, increasing the risk of developing noncommunicable diseases such as cardiovascular disease and type 2 diabetes mellitus $[50,51]$. Given this, among the six 
global nutrition targets established in 2012 by the World Health Assembly Resolution 65.6 to be met by 2025 is "to ensure that there is no increase in childhood overweight" [52].

A limitation of this study was not to investigate the children's food intake and physical activity pattern in the three analyzed periods, precluding for a more in-depth analysis based on the adequacy of energy and nutrient consumption.

In contrast to this limitation, the study provides up-todate data on the stunting and overweight prevalence in preschoolers and their temporal trends, obtained from adequately designed and children's representative samples from a Brazilian state.

\section{Conclusion}

During the analyzed period (1992 to 2015), there was a significant and continuous decrease in the stunting prevalence. At the same time, a substantial increase was observed in the overweight prevalence. Currently, stunting is a problem of low magnitude, while overweight has become a worrying public health problem.

Both socioeconomic and biological factors were identified as independently associated with stunting and with overweight, characterizing the etiological complexity of these conditions.

These findings should be considered when planning actions and public policies for the prevention of these nutritional disorders.

\section{Abbreviations \\ FANUT: Faculdade de Nutrição (Faculty of Nutrition).; UFAL: Universidade Federal de Alagoas (Federal University of Alagoas).; CNPq: Conselho Nacional de Desenvolvimento Científico e Tecnológico (National Council for Scientific and Technological Development).; FAPEAL: Fundação de Amparo à Pesquisa do Estado de Alagoas (Foundation for Research Support of the State of Alagoas).; HDI: Human Development Indexes; sd: Standard deviation; 95\% Cl: 95\% confidence interval; WHO: World Health Organization; PR: Prevalence ratios; haz: Height-for-age index; whz: Weight-for-height; PNDS- 2006: Pesquisa Nacional de Demografia e Saúde da Criança e da Mulher (National Survey of Demography and Health of Children and Women); UNICEF: United Nations Children's Fund}

\section{Acknowledgements}

The authors thank Professor Cesar Victora (Federal University of Pelotas, Brazil) for authorizing the use of the 1992 survey database. Article based on the master's degree dissertation of G.T. Albuquerque, presented to the Faculty of Nutrition, Federal University of Alagoas, in 2018.

\footnotetext{
Authors' contributions

HSF was involved in the study conception, and design, data interpretation, and final writing of the article. GTA performed data analysis and the initial paper draft. TRS, RLB, ALC, LECD and MLA participated in the data analysis and interpretation and the text revision. All authors read and approved the final manuscript.
}

\section{Funding}

H. S. Ferreira is a research fellow of the National Research Council (CNPq; grant \# 304964/2018-2). The 2015 survey received financial support from National Council for Scientific and Technological Development (CNPq; process \# 474381/2011-0) and Research Support Foundation of the State of Alagoas (FAPEAL; process \# 60030 000716/2013). The 2005 survey was funded by FAPEAL (Process \# 2003.31029448-0) and the Ministry of Health (Process \# 011/2004 PPSUS/AL). The funders played no role in the design of the study and collection, analysis, and interpretation of data and in writing the manuscript.

\section{Availability of data and materials}

The datasets used and/or analyzed during the current study are available from the corresponding author on reasonable request.

\section{Ethics approval and consent to participate}

The projects for 2005 (process \# 010102/0355) and 2015 surveys (process \# 09093012.0.0000.5013) were approved by the Research Ethics Committee of the Federal University of Alagoas. Written informed consent to participate was obtained from all children's mothers or guardians before data collection. The use of the database of the 1992 study was carried out with the consent of the holder of the rights of this material (Prof. Dr. Cesar Gomes Victora, from the Federal University of Pelotas, RS, Brazil).

\section{Consent for publication}

Not applicable.

\section{Competing interests}

The authors declare that they have no conflict of interest.

\section{Author details}

${ }^{1}$ Faculty of Nutrition, Federal University of Alagoas, Campus A.C. Simões, BR 104 Norte - Km 96.7 - Tabuleiro do Martins, CEP, Maceió, AL 57072-970, Brazil. ${ }^{2}$ Post-graduate Program in Nutrition, Federal University of Alagoas, Maceió, AL, Brazil. ${ }^{3}$ Post-graduate Program in Health Sciences, Federal University of Alagoas, Maceió, AL, Brazil.

Received: 30 August 2019 Accepted: 7 May 2020

Published online: 20 May 2020

\section{References}

1. Sartorius B, Sartorius K, Taylor M, Aagaard-Hansen J, Dukhi N, Day C, Ndlovu $N$, Slotow R, Hofman K. Rapidly increasing body mass index among children, adolescents and young adults in a transitioning population, South Africa, 2008-15. Int J Epidemiol. 2017.

2. Popkin BM, Corvalan C, Grummer-Strawn LM. Dynamics of the double burden of malnutrition and the changing nutrition reality. Lancet (London, England). 2020;395(10217):65-74

3. NCD Risk Factor Collaboration. Worldwide trends in body-mass index, underweight, overweight, and obesity from 1975 To 2016: a pooled analysis of 2416 population-based measurement studies in 128.9 million children, adolescents, and adults. Lancet (London, England). 2017; 390(10113):2627-42.

4. Dietz WH. Double-duty solutions for the double burden of malnutrition. Lancet (London, Engl). 2017;390(10113):2607-8.

5. Ferreira HS. Anthropometric assessment of children's nutritional status: a new approach based on an adaptation of Waterlow's classification. BMC Pediatr. 2020;20(1):65.

6. de Onis M, Branca F. Childhood stunting: a global perspective. Matern Child Nutr. 2016;12(Suppl 1):12-26.

7. World Health Organization (WHO). Reducing stunting in children: equity considerations for achieving the global nutrition targets 2025. Geneva: WHO; 2018.

8. Stewart CP, lannotti L, Dewey KG, Michaelsen KF, Onyango AW. Contextualising complementary feeding in a broader framework for stunting prevention. Matern Child Nutr. 2013;9(Suppl 2):27-45.

9. World Health Organization (WHO). Childhood stunting: challenges and opportunities: report of a webcast colloquium on the operational issues around setting and implementing national stunting reduction agendas. Geneva: WHO; 2014

10. Goudet SM, Bogin BA, Madise NJ, Griffiths PL. Nutritional interventions for preventing stunting in children (birth to 59 months) living in urban slums in low- and middle-income countries (LMIC). Cochrane Database Syst Rev. 2019;6:Cd011695.

11. Kumar S, Kelly AS. Review of childhood obesity: from epidemiology, etiology, and comorbidities to clinical assessment and treatment. Mayo Clin Proc. 2017;92(2):251-65. 
12. Moreira MA, Cabral PC, Ferreira HS, Lira PI. Overweight and associated factors in children from northeastern Brazil. J Pediatr. 2012;88(4):347-52.

13. Ferreira HS, Lucio GM, Assuncao ML, Silva BC, Oliveira JS, Florencio TM, Geraldes AA, Horta BL. High blood pressure among students in public and private schools in Maceio, Brazil. PloS One. 2015;10(11):e0142982.

14. Costa NS, Santos MO, Carvalho CPO, Assuncao ML, Ferreira HS. Prevalence and factors associated with food insecurity in the context of the economic crisis in Brazil. Curr Dev Nutr. 2017;1(10):e000869.

15. Relatório de Desenvolvimento Humano 2015. Ranking IDH Global 2014 [Human Development Report 2015. 2014 Global HDI Ranking]. http://www. br.undp.org/content/brazil/pt/home/idh0/rankings/idh-global.html.

16. Monteiro CA. A dimensão da pobreza, da fome e da desnutrição no Brasil [Dimension of Poverty, Hunger and Malnutrition in Brazil]. Estudos Avançados. 1995;9(24):195-207.

17. Victora CG, Barros FC, Tomasi E, Ferreira FS, MacAuliffe J, Silva AC, Andrade FM, Wilhelm L, Barca DV, Santana S. A saúde das crianças dos estados do Ceará, Rio Grande do Norte e Sergipe, Brasil: descrição de uma metodologia para diagnósticos comunitários [Child health in the States of Ceará, Rio Grande do Norte and Sergipe, Brazil: description of a methodology for the diagnosis of communities]. Rev Saude Publica. 1991;25:218-25.

18. Ferreira HS, Cesar JA, Assunção ML, Horta BL. Time trends (1992-2005) in undernutrition and obesity among children under five years of age in Alagoas state, Brazil. Cadernos Saúde Pública. 2013;29:793-800.

19. Ferreira HD, Luciano SC. Prevalence of extreme anthropometric measurements in children from Alagoas, northeastern Brazil. Rev Saude Publica. 2010;44(2):377-80.

20. World Health Organization (WHO): WHO child growth standards: length/ height for age, weight-for-age, weight-for-length, weight-for-height and body mass index-for-age, methods and development: WHO; 2006.

21. Instituto Brasileiro de Geografia e Estatística (IBGE), Coordenação de Geografia: Classificação e caracterização dos espaços rurais e urbanos do Brasil: uma primeira aproximação [Classification and characterization of rural and urban spaces in Brazil: a first approximation]. In. Rio de Janeiro: IBGE; 2017: 84.

22. Levels and trends in child malnutrition. Key findings of the 2015 edition. https://www.who.int/nutgrowthdb/jme_brochure2015.pdf?ua=1; https:// www.who.int/nutgrowthdb/2018-jme-brochure.pdf?ua=1.

23. Gonçalves M, Ferreira A: Saúde: objetivo 4: reduzir a mortalidade infantil; Objetivo 5: melhorar a saúde materna; Objetivo 6: combater HIV/AIDS, a malária e outras doenças. Belo Horizonte, MG: UFPA, PUC Minas/IDHS, PNUD; 2004

24. Instituto Brasileiro de Geografia e Estatística (IBGE) [Brazilian Institute of Geography and Statistics] Sistema IBGE de Recuperação Automática - SIDRA [IBGE Automatic Recovery System - SIDRA]. https://sidra.ibge.gov.br/tabela/6784 \#/n1/all/v/9812/p/all/d/v9812\%202/l/v "t+p/resultado. Accessed 12 May 2020.

25. United Nations Children's Fund. UNICEF Data: Monitoring the situation of children and women. Cross-sector Indicators. Brazil: Geographic Area; https://data.unicef.org/resources/data_explorer/unicef_f/?ag=UNICEF\&df= GLOBAL_DATAFLOW\&ver=1.0\&dq=BRA.CME_MRM0+CME_MRYOT4. \&startPeriod=1970\&endPeriod=2020. Accessed 12 May 2020.

26. Levels and trends in child malnutrition: key findings of the 2018 Edition of the Joint Child Malnutrition Estimates. https://www.who.int/nutgrowthdb/2 018-jme-brochure.pdf?ua=1.

27. Souza MFM, Malta DC, França EB, Barreto ML. Transição da saúde e da doença no Brasil e nas Unidades Federadas durante os 30 anos do Sistema Único de Saúde [changes in health and disease in Brazil and its states in the 30 years since the unified healthcare system (SUS) was created]. Ciência \& Saúde Coletiva. 2018;23:1737-50.

28. Brasil. Ministério da Saúde. Centro Brasileiro de Análise e Planejamento: Pesquisa Nacional de Demografia e Saúde da Criança e da Mulher - PNDS 2006: dimensões do processo reprodutivo e da saúde da criança [National Survey of Demography and Health of Children and Women - PNDS 2006: dimensions of the reproductive process and child health]. Brasilia: Ministério da Saúde; 2009.

29. Lima AL, Silva AC, Konno SC, Conde WL, Benicio MH, Monteiro CA. Causes of the accelerated decline in child undernutrition in northeastern Brazil (1986-1996-2006). Rev Saude Publica. 2010;44(1):17-27.

30. World Health Organization (WHO): Nutrition Landscape Information System (NLIS) country profile indicators: interpretation guide. 2010.

31. NAÇÕES UNIDAS: Relatório do Comitê Ad Hoc Pleno da vigésima sétima sessão especial da Assembléia Geral. In Nova York: ONU; 2002.

32. United Nations Children's Fund (UNICEF): Situação mundial da infância 2006: excluídas e invisíveis. In: Situação mundial da infância 2006: excluídas e invisíveis. edn.; 2005.
33. Brasil. Secretaria de Vigilância em Saúde: Saúde Brasil 2009: uma análise da situação de saúde e da agenda nacional e internacional de prioridades em saúde. Brasília: Ministério da Saúde; 2010.

34. Sousa LRM, Segall-Corrêa AM, Ville AS, Melgar-Quiñonez H. Food security status in times of financial and political crisis in Brazil. Cadernos Saúde Pública. 2019;35(7).

35. Pereira IFS, Andrade LMB, Spyrides MHC, Lyra CO. Estado nutricional de menores de 5 anos de idade no Brasil: evidências da polarização epidemiológica nutricional. Ciência Saúde Coletiva. 2017;22:3341-52.

36. Malik VS, Willett WC, Hu FB. Global obesity: trends, risk factors and policy implications. Nat Rev Endocrinol. 2013;9(1):13-27.

37. Silveira JA, Colugnati FA, Cocetti M, Taddei JA. Secular trends and factors associated with overweight among Brazilian preschool children: PNSN-1989, PNDS-1996, and 2006/07. J Pediatr. 2014;90(3):258-66.

38. Adamo KB, Ferraro ZM, Goldfield G, Keely E, Stacey D, Hadjiyannakis S, JeanPhilippe S, Walker M, Barrowman NJ. The maternal obesity management (MOM) trial protocol: a lifestyle intervention during pregnancy to minimize downstream obesity. Contemp Clin Trials. 2013;35(1):87-96.

39. Oliveira ACM, Pereira LA, Ferreira RC, Clemente APG. Estado nutricional materno e sua associação com o peso ao nascer em gestações de alto Risco [maternal nutritional status and its association with birth weight in high-risk pregnancies]. Ciência Saúde Coletiva. 2018;23:2373-82.

40. Drachler ML, Macluf SP, Leite JC, Aerts DR, Giugliani ER, Horta BL. Fatores de Risco Para sobrepeso em crianças no Sul do Brasil [risk factors for overweight in children from southern Brazil]. Cad Saude Publica. 2003;19(4): 1073-81.

41. Engstrom EM, Anjos LA. Relação entre o estado nutricional materno e sobrepeso nas crianças brasileiras [relationship between maternal nutritional status and obesity in Brazilian children]. Rev Saude Publica. 1996;30(3):233-9.

42. Dinsa GD, Goryakin Y, Fumagalli E, Suhrcke M. Obesity and socioeconomic status in developing countries: a systematic review. Obes Rev. 2012;13(11): 1067-79.

43. Gupta N, Goel K, Shah P, Misra A. Childhood obesity in developing countries: epidemiology, determinants, and prevention. Endocr Rev. 2012; 33(1):48-70.

44. Min J, Xue H, Wang VHC, Li M, Wang Y. Are single children more likely to be overweight or obese than those with siblings? The influence of China's one-child policy on childhood obesity. Prev Med. 2017;103:8-13.

45. Mansukoski L, Johnson W, Brooke-Wavell K, Galvez-Sobral JA, Furlan L, Cole TJ, Bogin B. Four decades of socio-economic inequality and secular change in the physical growth of Guatemalans. Public Health Nutr. 2019:1-11.

46. Castro MC, Massuda A, Almeida G, Menezes-Filho NA, Andrade MV, de Souza Noronha KVM, Rocha R, Macinko J, Hone T, Tasca R et al: Brazil's unified health system: the first 30 years and prospects for the future. Lancet (London, England) 2019.

47. The Lancet Global Health. Brazil enters the Bolsonaro zone. Lancet Glob Health. 2019;7(2):e160.

48. Albuquerque MV, Viana ALD, Lima LD, Ferreira MP, Fusaro ER, lozzi FL. Regional health inequalities: changes observed in Brazil from 2000-2016. Cien Saude Colet. 2017;22(4):1055-64.

49. Fenske N, Burns J, Hothorn T, Rehfuess EA. Understanding child stunting in India: a comprehensive analysis of socio-economic, nutritional and environmental determinants using additive quantile regression. PLoS One. 2013;8(11):e78692.

50. World Health Organization (WHO). Global Strategy on Diet, Physical Activity and Health. Childhood overweight and obesity. https://www.who.int/ dietphysicalactivity/childhood/en/. Accessed 12 May 2020.

51. World Health Organization (WHO). Global Nutrition Targets 2025: policy brief series (WHO/NMH/NHD/14.2). Geneva: WHO; 2014. https://www.who. int/nutrition/publications/globaltargets2025_policybrief_overview/en/. Accessed 12 May 2020.

52. World Health Organization (WHO): Global nutrition targets 2025: Policy brief series. In.: WHO; 2014.

\section{Publisher's Note}

Springer Nature remains neutral with regard to jurisdictional claims in published maps and institutional affiliations. 